\title{
Fourth-Generation Activity Theory: An Integrative Literature Review and Implications for Professional Communication
}

\author{
Clay Spinuzzi \\ University of Texas at Austin \\ clay.spinuzzi@utexas.edu
}

\author{
David Guile \\ University College London \\ d.guile@ucl.ac.uk
}

\begin{abstract}
Activity theory in its "third generation" (3GAT) has been used extensively to analyze case studies in professional communication and related fields such as information systems, workforce education, and computer-supported cooperative work. Yet 3GAT has known limits, and these limits are making it difficult to model, assess, and make recommendations for such cases. In this paper, we discuss these limitations, then overview and synthesize recent research pointing to a fourth generation of activity (4GAT). We find that this literature has two main foci: (1) Peer and social production and (2) Networked organization of labor and production. We conclude by offering implications for professional communication.
\end{abstract}

Index Terms - Fourth-generation activity theory, cultural-historical activity theory, 4GAT, CHAT.

\section{INTRODUCTION}

Over the past 20 years, "third generation" activity (also known as cultural-historical activity theory or CHAT), as developed by Yrjö Engeström and colleagues, has provided a sociocultural analytical framework for studying how organized human activity develops, as well as practices for intervening in and improving the participants' activity. The framework involves (1) mapping the object or material focus of an ongoing activity, along with elements such as the people who seek to transform it and the tools, rules, and division of labor that they use when cyclically transforming the object; (2) identifying developmental contradictions within and across the elements; and (3) identifying fruitful interventions that researchers and participants can take to address the contradictions and mutually improve outcomes. Interventions have included designing new tools, rules, and divisions of labor; rethinking and expanding the object; and involving new people in the ongoing activity.
3GAT's framework and tools have been applied to case studies in professional communication, information systems, computer-supported cooperative work (CSCW), and related fields, illuminating cases such as complex mediated work within and across organizations, especially in digitally mediated work and post-bureaucratic work. Examples of such cases include technology commercialization, coworking, and cross-organizational collaboration using digital tools.

However, 3GAT has built-in limits. Specifically, activity theorists have noted limitations that 3GAT faces when accounting for social production, peer production, and similar cases of post-bureaucratic work, cases that do not resemble traditional work with known cycles and an agreed-upon object. Unlike cases traditionally explored by activity theory (e.g., education, health, law, and other longterm, stabilized activities), these cases tend to be unsettled, unstable, and interconnected with many other activities (e.g., open source software, coworking, entrepreneurship, and client-focused projects). Such cases tend to include objects that are fractional rather than unified; emergent rather than established; and transformed through multiple, loosely synchronized cycles rather than a single developmental cycle.

For such cases, a small but growing body of literature explores the possibility of a fourth-generation activity theory. Yet this literature does not sketch out a coherent approach. In this paper, we review the 4GAT literature, examining these questions:

1. What problems do researchers attempt to solve with 4GAT?

2. How do researchers propose to develop 4GAT to solve these problems?

3. To what degree do these sources result in a coherent 4GAT?

4. How can 4GAT's development help the field of professional communication? 
Below, we overview activity theory and its limitations; describe our methodology for conducting this integrative literature review; overview our results in terms of our research questions; and, finally, discuss implications for professional communication.

\section{Activity Theory: Overview, Use, and Development}

Activity theory developed from the Soviet psychology of Lev Vygotsky and his colleagues. It provides a sociocultural, materialist account of individual and organizational development.

Engeström [9] characterizes activity theory as developing in three "generations." In the first generation (1GAT), Vygotsky developed the idea of mediation [51][9], in which an individual could control her own actions using physical or psychological tools. In 1GAT, "the unit of analysis remained individually focused. This was overcome by [2GAT, in which] Leont'ev explicated the crucial difference between an individual action and a collective activity" ([9], p.132). In 2GAT, Leontiev shifted his unit of analysis from Vygotsky's word meaning to object-oriented labor activity [25][26]. Finally, Engeström describes the then-emerging 3GAT, noting that "when activity theory went international, questions of diversity and dialogue between different traditions or perspectives became increasingly serious challenges," so 3GAT "needs to develop conceptual tools in order to understand dialogue, multiple perspectives, and networks of [at least two] interacting activity systems" ([9], pp.132-133).

3GAT was adopted in the West to provide a sociocognitive account of individual and organizational development, especially in areas mediated by information technologies, such as information studies, humancomputer interaction, computer-supported cooperative work, and professional communication. In professional communication in particular, we have used 3GAT to anchor qualitative case studies of how people communicate, coordinate, and collaborate in and across organizations.

Currently, searching for "activity theory" + "professional communication" on Google Scholar yields 1200 results. 3GAT has been used in professional communication to study information circulation and sharing in and across organizations (e.g., [43][44]); to supplement genre theory for understanding genres-inactivity (e.g., [6][28]); to examine, critique, and improve professional communication pedagogy (e.g., [21][29]); and to theorize, guide, critique, and improve industry-academic partnerships (e.g., [17][47]).

Yet these applications have also begun to expose 3GAT's limitations, specifically when applied to complex multi-activity collaborations with emergent objects. These limitations have also been noted in other areas using activity theory. To address them, activity theory arguably needs a fourth generation.

\section{Toward a Next Generation of Activity Theory: 4GAT Attempts and Limitations}

To address such cases, in 2009, Engeström suggested developing a fourth generation of activity theory (hereafter 4GAT). Whereas 3GAT "still treats activity systems as reasonably well-bounded, although interlocking and networked, structured units," 4GAT must address "social production and peer production," in which "the boundaries and structures of activity systems seem to fade away" and "The density and crisscrossing of processes makes the distinction between processes and structure somewhat obsolete" ([7] p. 309).

This call provided a general direction, but not a specific agenda. In the intervening ten years since Engeström issued this call, several scholars have attempted to sketch out requirements for 4GAT. However, these attempts have been relatively uncoordinated and have not resulted in a shared agenda. Instead, the efforts have fractured, applying to a number of different problems, including but not limited to peer/social/economic production; the networked organization of labor and production; emotion; subjectivity; dialogicality; social capital; and innovation. This fracturing has meant that efforts to develop a 4GAT have not coalesced into a shared developmental path. And without such a path, 4GAT may not develop in a way that allows us to adequately model, assess, and make recommendations for cases in professional communication. Here, we review the literature in order to identify groupings and a way forward.

\section{Methodology}

To better understand these attempts as a first step for developing a coherent agenda for developing a 4GAT, we conducted an integrative review of 4GAT literature. This review followed the specifications of integrative literature reviews in IEEE Transactions on Professional Communication.

In this section, we describe how we explored the existing literature on 4GAT. We begin by explaining our choice of the integrated literature review for answering our research questions:

- What problems do researchers attempt to solve with 4GAT?

- How do researchers propose to develop 4GAT to solve these problems?

- To what degree do these sources result in a coherent 4GAT?

- How can 4GAT's development help the field of professional communication?

We then discuss how we collected, analyzed, and validated the data that we describe in the next section of this review. 


\section{Choice of research methodology}

Although integrative literature reviews have not been common in professional communication, IEEE Transactions on Professional Communication has published a number of integrative literature reviews (e.g., [2][4]). In an integrative literature review, the author provides an interdisciplinary overview that has been systematically developed and that focuses on critique or interpretation rather than reporting [4]. For that reason, integrative literature reviews are particularly important for (although rare within) professional communication, an interdisciplinary field that draws from several others.

An integrative literature review is particularly apt for understanding 4GAT, which (a) is being developed across multiple fields and disciplines in parallel, with little coordination, (b) is being discussed with increasing frequency, and (c) has not yielded a single coherent account. Here, we attempt to systematically collect and coordinate literature across these fields and disciplines to identify trends across this emerging body of literature.

\section{How data were collected}

Because it is primarily intended for illumination purposes, this integrative literature review explains how relevant literature characterizes 4GAT and identifies the key themes in the literature. It is not intended as a critical analysis of the quality of the current literature.

To generate a list of potential literature, on January 14, 2019, we searched Google Scholar for the following terms. For all, we sorted by relevance:

- "fourth generation" + "activity theory" $-\mathrm{Guba}^{1}$ (390)

- "fourth generation" +Engeström -Guba (178)

- "4GAT" +"activity theory" (12)

We also searched Google Scholar for sources that cited Engeström's 2009 chapter and that included "fourth generation" (24).

We then discarded the following categories of sources:

- Sources that were false positives (for instance, they contained the phrases "fourth generation" and "activity theory," but not connected).

- Sources that mentioned the concept only in passing. For instance, Kimme Hea [24] mentions it in summarizing another scholar's argument.

- Sources that were not written in English, since we are monolingual English speakers.

We were left with 19 publications. We note here that other scholarship is developing activity theory to address similar problems, but has not explicitly characterized itself as developing a fourth generation, and thus did not show up in our data collection. For instance, Bodker \& Andersen
[3] discuss how to address multiple objects to which people serially direct attention.

To ensure coverage, we also performed these searches on Science Direct, the ACM Digital Library, IEEE Xplore, Springer Link, and Web of Science (cf. [52]). The searches did not result in additional sources.

\section{How data were analyzed}

After compiling a list of works, we manually evaluated full texts of the publications for relevance given the criteria established above. Next, we characterized the conclusions of each text reviewed. We specifically tracked the following issues, which related to our research questions:

1. Problems that researchers attempted to solve with 4GAT

2. How researchers proposed to develop 4GAT to solve these problems.

3. The degree to which these proposals interrelated with other proposals in the literature set.

\section{RESULTS}

Below, we first characterize the literature included in this review, then address the research questions.

\section{Literature included in this review}

After conducting the search for literature, we found just 19 publications that met the criteria, including 4 doctoral or master's theses, 4 proceedings papers, 11 articles, and 1 book chapter. These publications came from fields and disciplines such as professional communication, education, information systems, and sociology.

\section{Research Question 1: What problems do researchers attempt to solve with $4 G A T$ ?}

The publications clustered around two major strands and several minor strands (Table 1).

TABLE 1. LITERATURE INCLUDED IN THIS REVIEW.

\begin{tabular}{|c|c|}
\hline Strand & Source \\
\hline $\begin{array}{l}\text { 1. Peer and } \\
\text { social } \\
\text { production (5) }\end{array}$ & $\begin{array}{l}\text { Lotz-Sisitka, Pesanayi \& } \\
\text { Chikunda [27]; Mukute, } \\
\text { Mudokwani, McAllister, \& } \\
\text { Nyikahadzoi [33]; Nunez [35]; } \\
\text { Ploettner \& Tresseras [37]; } \\
\text { Yamazumi [53] }\end{array}$ \\
\hline $\begin{array}{l}\text { 2. Networked } \\
\text { organization of } \\
\text { labor and }\end{array}$ & $\begin{array}{l}\text { Dandoy [5]; Forsgren [11]; } \\
\text { Forsgren \& Bystrom [12]; Francis } \\
\text { \& Hardman [14]; Ivaldi, S. [18]; } \\
\text { Karanasios [22]; Novoa [34]; } \\
\text { Spinuzzi [44][45][46][47] }\end{array}$ \\
\hline
\end{tabular}

\footnotetext{
${ }^{1}$ We subtracted results with "Guba" because many false positives resulted from citations of Guba \& Lincoln's book Fourth generation evaluation.
} 


\begin{tabular}{|l|l|}
\hline $\begin{array}{l}\text { production } \\
(11)\end{array}$ & \\
\hline Other (3) & $\begin{array}{l}\text { Gleasure \& Morgan [15]; } \\
\text { Khayyat [23]; Moynihan [32] }\end{array}$ \\
\hline
\end{tabular}

Strand 1. Peer and social production: These five publications argue that 3GAT does not adequately address peer and social production, social production, and other non-institutional, voluntary, durable collaborations. They identify capitalism as a problem and seek alternatives to it, drawing on 3GAT-based interventionist research approaches such as Developmental Work Research and Change Laboratory. These publications thus interact with others that do not explicitly cite 4GAT (e.g., [10][38]).

Strand 2. Networked organization of labor and production: These 11 publications argue that 3GAT's unit of analysis and theoretical concepts do not adequately capture elements of networked organization. They argue for developing 4GAT to better address overlapping activities in which different logics, motives, and concepts are brought to bear on a shared fractional object. Thus these publications interact with others applying activity theory to post-bureaucratic work (e.g., [3][16][19][41][48]).

Other Strands: Finally, these three articles each address a separate problem: Emotion and identity; social capital; and motivation.

III. Research Question 2: How do researchers propose to develop 4GAT to solve these problems?

Strand 1. Peer and social production: These five sources propose to develop 4GAT to better understand peer and social production, in which individuals collaborate across or outside organizations and in which "the boundaries and structures of activity systems seem to fade away" ([7], p. 309).

Three sources propose developing 4GAT to provide alternatives to capitalism. In Plottner \& Tresseras' interview with Yrjo Engeström and Anna Sannino, Engeström flatly says: "The challenge of fourth generation of activity theory is alternatives to capitalism. How you build sustainable viable resilient alternatives to capitalism especially understood as the neoliberal global regime" ([37], p.93). Similarly, Mukute et al. [33] state that activity theory and actor-network theory both "point to the limitations of current problem-solving approaches that have been developed in and tend to serve a capitalist-based approach, which commodifies knowledge, natural resources, and life forms." (p.244). Finally, Lotz-Sisitka et al. [27] describe using fourth-generation objects to examine case studies in "in postcolonial, decolonizing societal contexts," case studies that "involve a reappropriation and a re-claiming of the commons and commonality under complex conditions of climate change and water scarcity" (p.1052). "The two case studies illuminate how via expansive learning in CHAT generative research processes, communities, formerly disenfranchised and left bereft of land, resources and other means of livelihoods are beginning to reclaim the commons through expansive learning and transformative agency - one bit at a time" (p.1052).

One source applies 4GAT to the peer production question of hacking in education. Yamazumi [53] notes the first three generations of activity theory, then predicts a fourth generation that can be deployed to study phenomena such as hacking, i.e., "the production of a relationship." "But how is it done? What kind of knotworking brings a good relationship? These ethical problems will become crucial subjects that theorists of the fourth generation should address" (p.13).

Finally, one source applies 4GAT to the question of domination more generally. Nunez [35] proposes to develop 4GAT by putting it in dialogue with critical realism to address latent dualities, with the goal of enabling self-empowerment and transforming "the very relations of domination that are in need of abolition, so that a new class of exploiters does not manifest itself" (p.94).

These sources are generally interventionist, in keeping with 3GAT (e.g., [20][49]). But whereas the 3GAT literature focuses on bounded organizations, the 4GAT literature focuses on intervening in runaway objects that no single stakeholder can completely apprehend. They emphasize developing equitable ways to produce such objects. Consequently, they generally focus on public institutions and goods (e.g., education and healthcare), since these objects involve multiple stakeholders with different interests. Three sources present 4GAT as providing alternatives to capitalism (cf. [10][38]).

Strand 2. Networked organization of labor and production: These 11 sources propose to develop 4GAT's unit of analysis and theoretical tools to account for projectoriented post-bureaucratic work. In these case studies, objects are fractional, multiple, and contested, and the authors seek to understand and improve work under new work conditions.

Two sources fall into the category of the theory and its history. Karanasios [31] discusses how activity theory has been applied to information systems research, as "an empirical method of understanding complex activities through the lens of activity systems" that is "distinct from its initiation as a way to address profound philosophical questions about the possibility of mind" (p.148). He argues that a 4GAT should explore and theorize digital technologies as tools; reconceptualize the activity system to "generate new activity-based theoretical understandings and perspectives"; reframe "the notion of objects to account for more expansive objects which are often the focus of IS studies"; better understand "new networks of connecting activity systems (e.g. inter-organizational work)"; examine congruences within and across activity systems; and "examine how IS can emancipate subjects" (pp.148-149). Spinuzzi [45] argues that 4GAT faces problems that include an expanded object; cyclical 
development within a network of activities that have their own separate cycles; and the fracturing of the object due to collective subjects.

Three sources fall into the category of educational applications. Francis and Hardman [14] examine "the use of social media to disrupt division of labour and give voice to students" (p.74). Here, 4GAT "is to accommodate the new types of collaborative activities that technological advances have enable[d], where collaboration happens not only within activity systems and within activity networks, but also across multiple networks of activity systems" (p.72). Novoa [34] describes research into design education, leading to "a 2016 undergraduate industrial design curriculum launch" in Australia (p.154). He notes that "4GCHAT upgrades communities of practice to a concept of collaborative communities particular to knowledge-intensive firms and learning that is cultural, contextual and historically based" (p.165); these communities are oriented toward interdisciplinary runaway objects; and their activity involves "co-configuration as a new scenario of dialogical knowledge production where designers, users and learners become guides, negotiators and boundary-spanners (individuals linking internal innovation systems)" (pp.165-166). He concludes that "Effective collaborative communities arise from cocreating values woven as knots in a grid of runaway objects, and contradictions that affect single discipline skills and participants (e.g. academics, students) in similar way to mycorrhizae-like activities" (p.166). Finally, Spinuzzi [47] describes an entrepreneurship training program, concluding that 4GAT "can develop productively by understanding emergent objects ... as multiple, dialogic, and transformed by synchronized activities. By examining such objects in these terms, we can better conceptualize the dynamics of activity networks united by these sorts of objects" (p.12).

Six sources are case studies set in post-bureaucratic workplaces. Three address coworking: Spinuzzi [46] describes overlapping configurations of activity networks. Dandoy [5] applies embodied phenomenology to "improve the emotional dimension of Cultural-Historical Activity Theory framework to explain the sense of community in new work configurations" (p.3). Ivaldi [18] notes that such "activities are characterized by simultaneous and reciprocal processes and the boundaries between the activity systems are more flexible and open" (p.57). One source explored how nonemployer firms cultivated subcontractor networks [44]. Two others [11][12] examine enterprise social media in project-based knowledge work, arguing that this work contributes "towards the fourth generation of activity theory, by analysing interrelated activity systems" ([11], p.211).

These sources connect to other literature applying activity theory to post-bureaucratic work. For instance, Guile [16] applies activity theory to the relationship between theory and practice, applied to the problem of education for the knowledge economy. Ivaldi et al. [19] and Spinuzzi et al. [48] apply activity theory to the development and practice of coworking. And Spinuzzi [41] applies activity theory to multiple cases of postbureaucratic work. Unlike Strand 1, in Strand 2 all of these sources are analytical rather than interventionist. Indeed, Guile [16] critiques Engeström for overstating the necessity and suitability of his interventionist methodology (p.124).

Other Strands: Finally, these three sources propose to develop 4GAT in various ways to address the problems that they advance: emotion and identity; social capital; and motivation.

Moynihan [32] focuses on emotion and identity, linking to 4GAT's "efforts to correct the neglect of subjective experience in social scientific research." This focus "makes [a] contribution to fourth generation CHAT with its emphasis upon how emotion and identity inform social interactions" (p.161), a contribution that provides "a theoretical framework that incorporates subjective identity and relational elements into the traditional model of Activity Theory interaction" (p.240). (Dandoy's [5] coworking study also addresses emotion and identity.)

Gleasure and Morgan [15] examine activity theory and social capital in crowdfunding. Noting Engeström's statement that 3GAT is best suited for well-bounded activities, they "advance the development of fourthgeneration AT by identifying and characterising the limitation at the heart of this struggle, specifically the lack of attention AT pays to ongoing macro-level and macromicro social influences" (p.505). After demonstrating how to apply social capital to crowdfunding, they propose "the integration of social capital as part of the move towards fourth-generation AT" in order to "explain phenomena such as crowdfunding that are characterised by collective intelligence and emergent structures" (p.507).

Finally, Khayyat [23] critiques 3GAT based on the critiques of Bakhurst [1]: specifically, that (a) the activity system does not incorporate motivation; (b) 3GAT does not acknowledge barriers or difficulties; (c) the 3GAT "object" is unclear; and (d) contradictions and connections are unclearly represented. Based on these critiques, Khayyat proposes to add elements such as "motivations, barriers, level of awareness, and effectiveness" (p.5), resulting in a redrawn triangle that incorporates those elements.

These sources each propose a direction to develop 4GAT. However, they do not interact substantially with each other or with other literature on 4GAT. Thus they do not appear to work toward coherent 4GAT development.

\section{Research Question 3: To what degree do these sources result in a coherent 4GAT?}

We have defined two major strands in the scholarship, plus miscellaneous sources outside those strands. In this section, we focus on the two major strands.

The two major strands have important differences. 
Aim: Strand 1 aims to provide alternatives to capitalism, while Strand 2 aims to better address postbureaucratic work within capitalist systems.

Stance: Strand 1 is explicitly interventionist, while Strand 2 is analytical (cf. [16]).

Scope: Strand 1 seeks to intervene in runaway objects, which are too large and diffuse to be fully apprehended by any single actor and thus involve a large set of stakeholders with different perspectives (cf. [8]). In contrast, Strand 2 addresses smaller-scope objects-specific projects with a limited, defined set of stakeholders - but understands these objects as fractional or multiple rather than multiperspectival (cf. [40][47]).

Yet the two strands also have parallel concerns and can support each other:

Boundaries. Both strands acknowledge a lack of strict boundaries between activities.

Dialogism. Both strands turn to Bakhtinian dialogism as a framework for examining the different positionalities and understandings of actors in the activities they study.

Given these parallel concerns, we believe that the two strands can support each other in the further development of 4GAT - particularly in professional communication.

\section{$V$. Research Question 4: How can 4GAT's development help the field of professional communication?}

Professional communication has used activity theory for grounding qualitative research, such as field studies and ethnographies of communication in workplaces, for over 20 years. In fact, three of the 4GAT sources cited here are field studies in professional communication [44][46][47]. In particular, many qualitative studies in professional communication have begun to explore post-bureaucratic work and its special challenges for professional communication (e.g., [13][36][50]). For these applications, Strand 2 offers a productive set of concepts for understanding post-bureaucratic work.

Yet Strand 1 also offers productive concepts for professional communication, which has examined peer and social production in open source software and support, Wikipedia, and other peer production sites, and social media [24][30][31]. In such cases, objects are inherently interdisciplinary and difficult to scope, and they are often produced without remuneration -- that is, although they are still produced within a capitalist system, they gesture toward the post-capitalist order that Engeström is interested in pursuing with Strand 1. For those reasons, Strand 1 potentially has much to offer professional communication studies as well.

\section{CONCLUSIONS, LIMITATIONS, AND SUGGESTIONS FOR FUTURE RESEARCH}

\section{Conclusions}

Although many are attempting to develop a 4GAT, these sources do not yet offer a unified definition or problem that all "4GAT" texts cluster around. That is, these different sources declare the intention to develop a new generation of AT, but they are not developing it in the same way or for the same purposes.

This development has taken various directions, but two major strands focus on different principles: alternatives to capitalism vs understanding work in post-bureaucratic capitalism. These strands react to some of the same analytical problems and are perhaps reconcilable, but point to different needs and imply different contributions, particularly to professional communication research. For instance, developing alternatives to capitalism involves taking an interventionist stance and building new interventionist tools for better understanding and guiding social and peer production as well as interdisciplinary public collaborations involving large, uncertain objects (such as open source software or global warming). In contrast, understanding post-bureaucratic work involves developing new analytical and conceptual tools.

\section{Limitations}

Activity theory is being developed in other publications that do not use keywords such as "fourth-generation activity theory" or "4GAT." Such publications were not gathered in this literature review. This review cannot capture all such developments, yet those developments will also impact 4GAT.

\section{Suggestions for future research}

4GAT is being mentioned more than developed in the literature; its development has been slow and isolated. We expect that situation to change as the existing 4GAT publications (mostly very recent) become more widely read and cited. These publications, we believe, will generate a common orientation and set of responses, leading to greater coherence across the literature. We suggest periodically checking in on this development.

In professional communication research, we are concerned with both of the major strands in the literature: peer and social production as well as post-bureaucratic work. Thus professional communication in particular can benefit from further development of 4GAT. At the same time, professional communication may have specific disciplinary requirements, demanding specific developments from 4GAT.

\section{REFERENCES}

[1] D. Bakhurst, "Reflections on activity theory," Educ. Rev., vol. 61, no. 2, pp. 197-210, May 2009.

[2] T. Batova, "Work Motivation in the Rhetoric of Component Content Management," J. Bus. Tech. Commun., vol. 32, no. 3, pp. 308-346, 2018.

[3] S. Bødker and P. B. Andersen, "Complex mediation," Human-Computer Interact., vol. 20, pp. 353-402, 2005. 
[4] D. Clark, "Content Strategy: An Integrative Literature Review,” IEEE Trans. Prof. Commun., vol. 59, no. 1, pp. 7-23, 2016.

[5] A. Dandoy, "When Merleau-Ponty meets Engeström in coworking spaces," 2017.

[6] H. Ding, "The Use of Cognitive and Social Apprenticeship to Teach a Disciplinary Genre: Initiation of Graduate Students Into NIH Grant Writing," Writ. Commun., vol. 25, no. 1, pp. 352, Jan. 2008.

[7] Y. Engeström, "The future of activity theory: A rough draft," in Learning and expanding with activity theory, A. Sannino, $\mathrm{H}$. Daniels, and K. Gutierrez, Eds. New York: Cambridge, 2009, pp. 303-328.

[8] Y. Engeström, From Teams to Knots: Studies of Collaboration and Learning at Work. New York: Cambridge University Press, 2008.

[9] Y. Engeström, "Developmental work research as educational research: Looking ten years back and into the zone of proximal development," Nord. Pedagog., vol. 16, pp. 131-143, 1996. [10] Y. Engeström and A. Sannino, "Expansive learning on the move: insights from ongoing research / El aprendizaje expansivo en movimiento: aportaciones de la investigación en curso," Infanc. y Aprendiz., vol. 39, no. 3, pp. 401-435, 2016.

[11] E. K. Forsgren, "Project-based knowledge work: A contextualised view through the lens of activity theory," University of Boras, 2018.

[12] E. Forsgren and K. Byström, "Multiple social media in the workplace: Contradictions and congruencies," Inf. Syst. J., no. July, pp. 1-23, 2017.

[13] S. Fraiberg, "Start-Up Nation: Studying Transnational Entrepreneurial Practices in Israel's Start-Up Ecosystem," $J$. Bus. Tech. Commun., vol. 31, no. 3, pp. 350-388, 2017. [14] S. Francis and J. Hardman, “\# Rhodesmustfall : Using Social Media To 'Decolonise' Learning Spaces for South African Higher Education Institutions : a Cultural Historical Activity Theory Approach," South African J. High. Educ., vol. 32, no. 4, pp. 66-80, 2018.

[15] R. Gleasure and L. Morgan, "The pastoral crowd: Exploring self-hosted crowdfunding using activity theory and social capital," Inf. Syst. J., vol. 28, no. 3, pp. 489-515, 2018. [16] D. Guile, The Learning Challenge of the Knowledge Economy. Boston: Sense Publishers, 2010.

[17] K. Gygi and M. Zachry, "Productive tensions and the regulatory work of genres in the development of an engineering communication workshop in a transnational corporation," $J$. Bus. Tech. Commun., vol. 24, no. 3, pp. 358-381, 2010. [18] S. Ivaldi, "Understanding coworking: Between typology and contradiction," Università Cattolica del Sacro Cuore di Milano, 2017.

[19] S. Ivaldi, I. Pais, and G. Scaratti, "Coworking(s) in the plural: Coworking spaces and new ways of managing," in The new normal of working lives: Critical studies in contemporary work and employment, S. Taylor and S. Luckman, Eds. Cham, Switzerland: Palgrave Macmillan, 2018, pp. 219-241.
[20] S. Ivaldi and G. Scaratti, "The formation of germ cell for organizational learning," J. Work. Learn., vol. 28, no. 4, pp. 224-244, 2016.

[21] D. Kain and E. Wardle, "Building context: Using activity theory to teach about genre in multi-major professional communication courses," Tech. Commun. Q., vol. 14, no. 2, pp. 113-139, Apr. 2005.

[22] S. Karanasios, "Toward a unified view of technology and activity: The contribution of activity theory to information systems research," Inf. Technol. People, vol. 31, no. 1, pp. 134$155,2018$.

[23] M. Khayyat, "A Proposed Model for the Fourth Generation of Activity Theory to be Applied on the Smart City Research Introduction and Historical Background of Activity Theory," in Ais Pre-Icis Workshop On Iot \& Smart City Challenges And Applications, ISCA 2016, 2016, pp. 1-9.

[24] A. C. Kimme Hea, "Social Media in Technical Communication," Tech. Commun. Q., vol. 23, no. 1, pp. 1-5, 2014.

[25] A. Kozulin, Vygotsky's Psychology: A Biography of Ideas. Boston: Harvard University Press, 1999.

[26] A. N. Leontiev, "Study of the environment in the pedological works of LS Vygotsky: a critical study," J. Russ. East Eur. Psychol., vol. 43, no. 4, pp. 8-28, 2005.

[27] H. Lotz-Sisitka, T. Pesanayi, and C. Chikunda, "Building commonality: Navigating historically situated power relations in CHAT expansive learning research," in Agentive Learning for Sustainability and Equity: Communities, Cooperatives and Social Movements as Emerging Foci of the Learning Sciences, 2016, pp. 1052-1053.

[28] M. Luzon, "Genre analysis in technical communication," IEEE Trans. Prof. Commun., vol. 48, no. 3, p. 285295, 2005.

[29] L. D. McNair and M. C. Paretti, "Activity Theory, Speech Acts, and the 'Doctrine of Infelicity': Connecting Language and Technology in Globally Networked Learning Environments," $J$. Bus. Tech. Commun., vol. 24, no. 3, pp. 323-357, Apr. 2010.

[30] M. Morain and J. Swarts, "YouTutorial: A framework for assessing instructional online video," Tech. Commun. $Q$., vol. 21, no. 1, pp. 6-24, 2012.

[31] J. T. Morgan and M. Zachry, "Negotiating with angry mastodons," in Proceedings of the 16th ACM international conference on Supporting group work - GROUP '10, 2010, pp. 165-168.

[32] T. J. Moynihan, “Covert conversations: Disciplined improvisation and meaning-making in the masters (MA) supervisory relationship," University College Cork, 2013. [33] M. Mukute, K. Mudokwani, G. McAllister, and K. Nyikahadzoi, "Exploring the Potential of Developmental Work Research and Change Laboratory to Support Sustainability Transformations: A Case Study of Organic Agriculture in Zimbabwe," Mind, Cult. Act., vol. 25, no. 3, pp. 229-246, 2018. [34] M. Novoa, "Innovating Industrial Design Curriculum in a Knowledge-Based, Participatory and Digital Era," Des. Technol. Educ. An Int. J., vol. 23, no. 3, pp. 154-204, 2018. 
[35] I. Nunez, "Critical Realist Activity Theory," University of London, 2012.

[36] S. Pigg, J. T. Grabill, B. Brunk-Chavez, J. L. Moore, P. Rosinski, and P. G. Curran, "Ubiquitous Writing, Technologies, and the Social Practice of Literacies of Coordination," Writ.

Commun., vol. 31, no. 1, pp. 91-117, 2014.

[37] J. Ploettner and E. Tresseras, "An interview with Yrjö Engeström and Annalisa Sannino on activity theory," Bellaterra J. Teach. Learn. Lang. Lit., vol. 9, no. 4, pp. 87-98, 2016.

[38] A. Sannino and Y. Engeström, "Cultural-historical activity theory: founding insights and new challenges," Cult. Psychol., vol. 14, no. 3, pp. 43-56, 2018.

[39] A. Sannino and B. Sutter, "Cultural-historical activity theory and interventionist methodology: Classical legacy and contemporary developments," Theory Psychol., vol. 21, no. 5, pp. 557-570, 2011.

[40] C. Spinuzzi, "Losing by Expanding: Corralling the Runaway Object," J. Bus. Tech. Commun., vol. 25, no. 4, pp. 449-486, 2011.

[41] C. Spinuzzi, All edge: Inside the new workplace networks. Chicago: University of Chicago Press, 2015.

[42] C. Spinuzzi, Network: Theorizing knowledge work in telecommunications. New York: Cambridge University Press, 2008.

[43] C. Spinuzzi, Tracing genres through organizations: A sociocultural approach to information design. Cambridge, MA: MIT Press, 2003.

[44] C. Spinuzzi, "How Nonemployer Firms Stage-Manage AdHoc Collaboration: An Activity Theory Analysis," Tech. Commun. Q., vol. 23, no. 2, pp. 88-114, 2014.

[45] C. Spinuzzi, "From superhumans to supermediators: Locating the extraordinary in CHAT," in Questioning Vygotsky's Legacy: Scientific Psychology or Heroic Cult, A. Yasnitsky, Ed. New York: Routledge, 2018, pp. 137-166.

[46] C. Spinuzzi, "Working Alone, Together: Coworking as Emergent Collaborative Activity," J. Bus. Tech. Commun., vol. 26, no. 4, pp. 399-441, 2012.

[47] C. Spinuzzi, “'I Think You Should Explore the Kinky Market': How Entrepreneurs Develop Value Propositions as Emergent Objects of Activity Networks," Mind, Cult. Act., vol. 24, no. 3, pp. 258-272, 2017.
[48] C. Spinuzzi, Z. Bodrožić, G. Scaratti, and S. Ivaldi, "'Coworking is about community' but what is 'community' in coworking?,” J. Bus. Tech. Commun., vol. 33, no. 2, pp. 1-29, 2019.

[49] B. Sutter, "How to analyze and promote developmental activity research?," Theory Psychol., vol. 21, no. 5, pp. 697-714, 2011.

[50] J. Swarts, "Composing Networks: Writing Practices on Mobile Devices," Writ. Commun., vol. 33, no. 4, pp. 385-417, 2016.

[51] L. S. Vygotsky, Mind in society: The development of higher psychological processes. Cambridge: Harvard University Press, 1978.

[52] F. Wiser, C. Durst, and N. Wickramasinghe, "Using Activity Theory Successfully in Healthcare: A Systematic Review of the Theory's Key Challenges to Date," in Proceedings of the 52nd Hawaii International Conference on System Sciences, 2019, pp. 882-891.

[53] K. Yamazumi, "Expansive learning approach to school change," in International Workshop: Activity Theory And Learning At Work, 2007, p. 9.

\section{ABOUT THE AUTHORS}

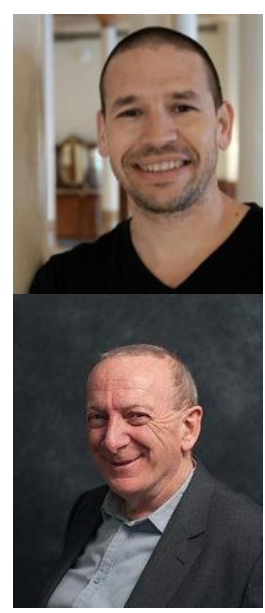

Clay Spinuzzi is a professor at the University of Texas at Austin. He studies professional communication in and between organizations via qualitative field studies.

David Guile is Professor of Education and Work and Co-Director of the Centre for Engineering Education at UCLInstitute of Education. He is interested in the changing relationship between work and technology, with special reference to professional and vocation learning. 